\title{
Fragility in Network Systems: An Empirical Investigation
}

Tsutomu Ito*, Katsuhiko Takahashi, Katsumi Morikawa, Takao Ito Graduate School of Engineering, Hiroshima University, 1-4-1 Kagamiyama,

Higashi-Hiroshima, 739-8527, Japan

E-mail: fw.eldorado.500cuin@gmail.com

Rajiv Mehta

School of Management, New Jersey Institute of Technology, University Heights, Newark, New Jersey, 07102-1982, U.S.

Seigo Matsuno

Department of Business and Administration, Ube National College of Technology, Tokiwadai 2-14-1 Ube, Yamaguchi, 755-0096, Japan

Makoto Sakamoto

Faculty of Engineering, University of Miyazaki, 1-1 Gakuen Kibanadai-Nishi, Miyazaki, 889-2192, Japan

\begin{abstract}
A survey of the relevant literature reveals that a plethora of network analytic facets, such as degree, eigenvalue, density, block, cluster, have been developed and employed to further our understanding of network structures. To extend our understanding of network systems, additional dimensions need to be identified that shed light on the dynamic processes among individual member nodes within network structures. Within the context of network systems, this paper proposes a new concept of fragility. More specifically, it develops and empirically tests a mathematical model of fragility from the standpoint of how ties among network members significantly influence corporate performance, thus uniquely contributing to extant knowledge. Using data drawn from two well-known network organizations, Mazda and Toyota, this research attempts to shed light on the relationship between degree and fragility, to confirm the validity of the new concept as well as enabling a contrast of Mazda and Toyota's network structures. Based on the findings, the managerial implications are discussed, the study limitations are identified and directions for further research are suggested.
\end{abstract}

Keywords: degree, fragility, Keiretsu, relationship, Yokokai.

\section{Introduction}

As in sociology and psychology, many mathematical models have been developed to increase our understanding of the organizational sciences. For instance, relative to the prominence of Keiretsu organizations, which play a dominant role in the Japanese economy, researchers have not devoted much attention on conducting empirical investigations to increase our understanding of these networks. While studies on Keiretsu have garnered greater attention and empirical studies have started to emerge in scholarly research journals, still these investigations can be 
considered fragmentary and sparse [1-2]. Being an additional organizational form within the context of networked structures, more recently dimensions, such as momentum [3], centrality [4-5], transactional relationships [6-7], capital relationships [8-9], Euclidean distance [10], cross shareholdings [11], and capacity [5], have revealed the static nature of relationships among individual actors relative to other members within the whole network. However, dynamic processes are considered to be even more salient in the organizational sciences and allied fields. A review of the literature suggests that newer models and paradigms illustrating the dynamic processes between network participants are more desirable. Accordingly, this paper proposes, measures and illustrates how the new concept of fragility, which is theoretically grounded as well as rooted in a systematic repeated trial and error assessment, has an impact on degree and corporate performance.

Drawing data from two well-known network organizations, Mazda's Yokokai and Toyota's Kyohokai from 2004 to 2007, the purpose of this research endeavor is to calculate and ascertain the relationship between fragility, degree and sales, thus confirming the validity of new model. Further, the relationship between fragility and corporate performance is also assessed, which forms the basis of the managerial implications discussed in the manuscript. More specifically, this paper makes a unique contribution to extant thought by: 1) Defining the concept of fragility, 2) Discussing the nature of the relationship between degree and corporate performance, and 3) Empirically testing the dimensional differences between fragility and corporate performance. Thus, this empirical investigation enables Mazda's networked organization to be compared and contrasted with Toyota's network constellation.

This paper is structured as follows. Section 2 reviews the literature focusing on network analysis. In section 3, the paper explicates the calculation of degree and fragility. Section 4 discusses our findings based on which the study limitations are identified and directions for further research are proffered in the final section.

\section{Background and Literature Review}

As noted earlier, indexes, such as momentum, centrality, transactional relationships, capital relationships, Euclidean distance, cross shareholdings, and capacity, have been used widely in empirical research to measure different dimensions of organizational networks. Comprising a most basic facet of centrality, degree was firstly proposed by Nieminen [12] in his research on organizational constellations.
Simply put, degree is defined as the number of links incident upon a node in a graph. In real society, most of the relationships between members are considered to be mutual. Furthermore, nodes within a network are known to interact with each other. Consequently, direction with weight have been commonly employed to analyze different phenomena within social networks. In this context, Freeman proposed a new index of entire degree, which identifies the centrality of the whole network [13].

More recently, Ito and Sakamoto proposed a new approach to identify the importance of each individual node based on Freeman's model [14], but noted that much more research is necessary to fully understand keiretsu constellations. Although the relationships between network members can be manifest in the form of equity ties, personal ties, transactional ties and workflow ties, this study examines transactions within a network to reveal the nature of the relationships between business ties and corporate performance. More specifically, owed to the sparsity of knowledge, this investigation contributes to the literature by advancing a new procedure for measuring the interrelationships between members of a keiretsu by suggesting the new concept of fragility to be a determinant of corporate performance.

\section{Research Method and Hypotheses}

Two concepts are applied in this paper: degree and fragility.

\subsection{Degree and Fragility}

Degree, as one of the basic indices of centrality, is considered as the basic index in network analysis. It can be calculated as follows [12].

where

$$
C_{D}\left(p_{k}\right)=\sum_{i=1}^{n} a\left(p_{i}, p_{k}\right)
$$

$i \neq k$;

$\mathrm{a}\left(\mathrm{p}_{\mathrm{i}}, \mathrm{p}_{\mathrm{k}}\right)=1$ if and only if $\mathrm{p}_{\mathrm{i}}$ and $\mathrm{p}_{\mathrm{k}}$ are connected by a line; (the percentage data are adopted in this paper.)

$\mathrm{a}\left(\mathrm{p}_{\mathrm{i}}, \mathrm{p}_{\mathrm{k}}\right)=0$ otherwise.

In an asymmetric network, two indexes of out-degree and in-degree should be calculated.

In transactional network, the value of degree is the percentage of transaction of parts maker $i$ with any other firms. Accordingly, out-degree means parts maker $i$ sells parts to other firm $j$ and/or car makers, and indegree refers to parts maker $i$ purchases parts from other 
firm $k$ and/or car makers. For instance, NSK Ltd., an enterprise specializing producing bearing, purchases parts of anti-vibration rubber from Kurashiki Kako Co., Ltd., and sells its products to car makers. Therefore, out-degree is associated with sales while in-degree is associated with sales indirectly. Thus, selling parts to keiretsu members will increase sales revenues while buying parts from other firms in the same keiretsu will be associated with greater sales indirectly. Accordingly, the following hypotheses are posited.

\section{H1: Higher levels of out-degree is associated with} increased sales.

H2: Higher levels of in-degree is associated with increased sales.

Fragility is a physical term that characterizes how rapidly the dynamics of a material slow down as it is cooled toward the material transition [15]. Accordingly, fragility, which is defined as the ratio of the entire degree of and the entire degree after moving a specific node, is mathematically expressed as:

where

$$
F(p)=\frac{C_{D}(\bar{p})-C_{D}}{C_{D}}
$$

$\mathrm{C}_{\mathrm{D}}$ : Entire degree of a given network;

$\mathrm{C}_{\mathrm{D}}(\bar{p})$ : Entire degree after removing node $\mathrm{p}$.

The equation of the entire network is defined as below [13].

$$
C_{D}=\frac{\sum_{i=1}^{n}\left[C_{D}\left(P^{*}\right)-C_{D}\left(P_{i}\right)\right]}{n^{2}-3 n+2}
$$

where

$$
C_{D}\left(p^{*}\right)=\max C_{D}\left(p_{i}\right)
$$

Fragility could be considered as a concept of structural importance. High fragility means the entire degree after moving a specific node $i$ is larger than the entire degree. Node $i$ is a weak point if the entire degree after moving the node $i$ is larger than the entire degree including the node $i$. Therefore, if a member of the keiretsu, which is considered to be vulnerable, is removed from the constellation, the value of degree of the keiretsu is reduced, which, in turn, can negatively impact sales revenues. Thus, the following hypothesis is proposed:
H3: Higher levels of fragility is associated with lower sales.

\subsection{Data Collection}

Widely considered as successful examples of prominent Japanese networked organizations, data were drawn from Toyota's Kyohokai and Mazda's Yokokai from 2004 to 2007 to establish the status quo of keiretsu as well as longitudinally ascertain changes in their keiretsu structure.

Japanese Keiretsu (e.g., Toyota, Nissan, and Mazda's networks) are known to comprise multifarious members. It is widely acknowledged that firms are reluctant to share financial information about themselves and their members due to confidential considerations that may have competitive implications. Moreover, key informants from the focal and member firms have to painstakingly research and provide relevant data from their management information systems, which is extremely time consuming and expensive. Further complicating these matters is that the data have to be cross-validated from other member firms within each respective network. Moreover, the longitudinal data were even cross-validated from on-line financial databases, thus enhancing the reliability of the data-set. As a result of this albeit onerous task, a complete set of valid, reliable and useable data were only available for the specified 2004-2007 period from Toyota's Yokokai and Mazda's Kyohokai.

Both of these keiretsu organizations include singletons, which refers to a partner firm in the keiretsu that has no relationship with other member firms. However, singletons were removed from the data-set because they have no impact on the calculation of network indexes. Data on Toyota's Kyohokai and Mazda's Yokokai from 2004 to 2007is reported in Table 1.

Table 1. Firms in Yokokai and Kyohokai.

\begin{tabular}{r|r|r|r|r}
\hline \multirow{2}{*}{} & \multicolumn{2}{|c|}{ Firm in Yokokai } & \multicolumn{2}{c}{ Firm in Kyohokai } \\
\cline { 2 - 5 } & Total & \multicolumn{1}{c}{ Singleton } & \multicolumn{1}{c}{ Total } & \multicolumn{1}{c}{ Singleton } \\
\hline 2004 & 188 & 97 & 215 & 93 \\
\hline 2005 & 191 & 89 & 216 & 97 \\
\hline 2006 & 190 & 92 & 213 & 93 \\
\hline 2007 & 189 & 104 & 213 & 101 \\
\hline
\end{tabular}


Table 2. Results of out-degree and in-degree-sales regression model.

\begin{tabular}{|c|c|c|c|c|c|c|c|c|}
\hline \multirow[b]{3}{*}{ Sales } & \multicolumn{8}{|c|}{ Models } \\
\hline & \multicolumn{4}{|c|}{ Yokokai } & \multicolumn{4}{|c|}{ Kyohokai } \\
\hline & 2004 & 2005 & 2006 & 2007 & 2004 & 2005 & 2006 & 2007 \\
\hline Out-degree & & & & & & & & \\
\hline Partial regression coefficient & 5153.172 & 7124.583 & -8079.95 & -15695.4 & -7537.79 & -4468.46 & -3779.68 & -3619.42 \\
\hline Standard coefficient & 0.0645 & 0.0904 & -0.0964 & -0.1447 & 0.1133 & -0.0624 & -0.0471 & -0.0389 \\
\hline t value & 0.8611 & 1.4957 & -1.0425 & -1.5971 & -2.7502 & -1.5524 & -1.2655 & -0.9838 \\
\hline Probability & 0.3919 & 0.1384 & 0.3003 & 0.1146 & 0.007 & 0.1238 & 0.2087 & 0.3277 \\
\hline Correlation coefficient & -0.4908 & -0.3858 & -0.4298 & -0.3185 & -0.4726 & -0.4668 & -0.4388 & -0.448 \\
\hline Partial correlation coefficient & 0.0983 & 0.1601 & -0.1151 & -0.8137 & -0.2615 & -0.1557 & -0.1262 & -0.1015 \\
\hline In-degree & & & & & & & & \\
\hline Partial regression coefficient & 14162.85 & 7124.583 & 9322.689 & 20726.5 & 6465.408 & 8166.002 & 9597.788 & 11958.24 \\
\hline Standard coefficient & 0.8968 & 0.9221 & 0.6465 & 0.6141 & 0.872 & 0.9057 & 0.9211 & 0.922 \\
\hline $\mathrm{t}$ value & 11.9655 & 15.2559 & 6.9917 & 6.7759 & 21.1592 & 22.5426 & 24.7341 & 23.3415 \\
\hline Probability & 0 & 0 & 0 & 0 & 0 & 0 & 0 & 0 \\
\hline Correlation coefficient & 0.8569 & 0.8754 & 0.6962 & 0.655 & 0.9187 & 0.9336 & 0.9411 & 0.9393 \\
\hline Partial correlation coefficient & 0.8082 & 0.8559 & 0.6135 & 0.6214 & 0.9016 & 0.9164 & 0.9277 & 0.9242 \\
\hline Coefficient of determination $\left(\mathrm{R}^{2}\right)$ & 0.73677 & 0.77231 & 0.49155 & 0.44836 & 0.85474 & 0.87464 & 0.88753 & 0.88346 \\
\hline Multiple correlation coefficient & 0.85835 & 0.87881 & 0.70111 & 0.6696 & 0.92452 & 0.93522 & 0.94209 & 0.93992 \\
\hline F value & 106.362 & 144.1595 & 39.1543 & 29.6667 & 303.038 & 338.3998 & 390.6121 & 352.4917 \\
\hline Degree of freedom & 2,76 & 2,85 & 2,81 & 2,73 & 2,103 & 2,97 & 2,99 & 2,93 \\
\hline $\mathrm{AIC}$ & 2441.18 & 2706.92 & 2678.46 & 2466.46 & 3182.65 & 3007.13 & 3078.19 & 2929.59 \\
\hline DW ratio & 1.9331 & 1.6531 & 2.5664 & 2.4682 & 1.5609 & 1.507 & 1.4393 & 1.3817 \\
\hline Data number & 79 & 88 & 84 & 76 & 106 & 100 & 102 & 96 \\
\hline
\end{tabular}

Table 3. Results of fragility-sales regression model.

\begin{tabular}{|c|c|c|c|c|c|c|c|c|}
\hline \multirow[b]{3}{*}{ Sales } & \multicolumn{8}{|c|}{ Models } \\
\hline & \multicolumn{4}{|c|}{ Yokokai } & \multicolumn{4}{|c|}{ Kyohokai } \\
\hline & 2004 & 2005 & 2006 & 2007 & 2004 & 2005 & 2006 & 2007 \\
\hline Fragility & & & & & & & & \\
\hline Partial regression coefficient & -2286318 & -2246640 & -102605 & -1996633 & -19942684.1 & -22446825.7 & -26007968.4 & -29733934.04 \\
\hline Standard coefficient & -0.2154 & -0.1958 & -0.0177 & -0.1262 & -0.7684 & -0.7656 & -0.7752 & -0.7798 \\
\hline t value & -1.9353 & -1.8513 & -0.1603 & -1.0945 & 12.2438 & -11.7819 & -12.2705 & -12.0763 \\
\hline Probability & 0.0566 & 0.0676 & 0.873 & 0.2773 & 0 & 0 & 0 & 0 \\
\hline Correlation coefficient & -0.2154 & -0.1958 & -0.0177 & -0.1262 & -0.7684 & -0.7656 & -0.7752 & -0.7798 \\
\hline Partial correlation coefficient & -0.2154 & -0.1958 & -0.0177 & -0.1262 & -0.7684 & -0.7656 & -0.7752 & -0.7798 \\
\hline Coefficient of determination $\left(\mathrm{R}^{2}\right)$ & 0.04638 & 0.03833 & 0.00031 & 0.01593 & 0.59041 & 0.58617 & 0.6009 & 0.60807 \\
\hline Multiple correlation coefficient & 0.21537 & 0.19577 & 0.01770 & 0.12621 & 0.76838 & 0.76562 & 0.77518 & 0.77979 \\
\hline$F$ value & 3.74529 & 3.42737 & 0.0257 & 1.19787 & 149.9108 & 138.81668 & 150.56441 & 145.83724 \\
\hline Degree of freedom & 1,77 & 1,86 & 1,82 & 1,74 & 1,104 & 1,98 & 1,100 & 1,94 \\
\hline AIC & 2540.88 & 2831.71 & 2733.25 & 2508.45 & 3290.54 & 3124.56 & 3205.68 & 3044.02 \\
\hline DW ratio & 1.2302 & 1.1155 & 0.9671 & 1.1641 & 0.9158 & 0.9119 & 0.8992 & 0.9052 \\
\hline Data number & 79 & 88 & 84 & 76 & 106 & 100 & 102 & 96 \\
\hline
\end{tabular}

A diagrammatic representation of the inter-firm transactional relationships in 2007 is illustrated in Fig. 1.

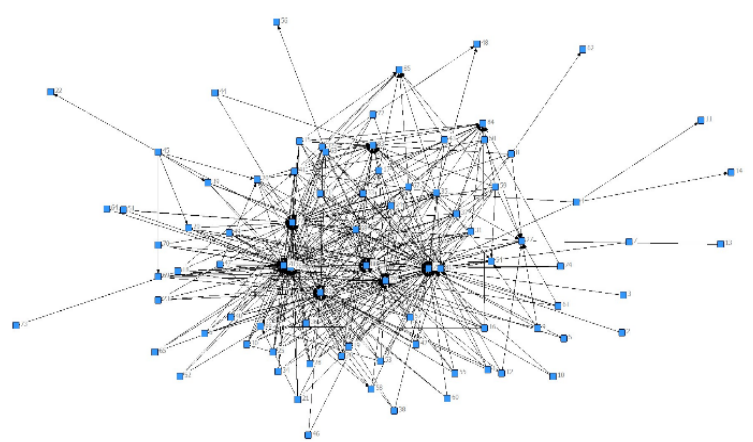

Fig. 1. Transaction network of Yokokai in 2007.

\section{Results and Discussion}

Using regression analysis, we first tested the relationship between out-degree and in-degree as determinants of sales. The results of out-degree and indegree-sales regression model is shown in Table 2.

\subsection{Sales and out-degree and in-degree}

All the probabilities of in-degree are significant while out-degree are not significant except for Kyohokai in 2004. Thus, evidently in-degree has a statistically significant impact on sales. In contrasting the results of the Yokokai, the correlation coefficients as well as the coefficients of determination are higher. Thus, it can be inferred that the regression model of Kyohokai has 
stronger power to explain the relationship between indegree and corporate performance-as measured by sales. Hence, the results with regard to $\mathrm{H} 1$ show that there is no association between out-degree and sales revenues. However, $\mathrm{H} 2$ is verified because there is a strong association between sales and in-degree. Specifically, Table 2 indicates that the difference between Yokokai and Kyohokai looks similar, but different in-degree.

\subsection{Sales and Fragility}

Fragility can also help distinguish the difference between Yokokai and Kyohokai. The results of fragility-sales regression model is shown in Table 3.

Compared with Yokokai, all the probabilities of fragility from 2004 to 2007 are statistically significant, and coefficients of determination are higher. Thus, the model assumptions of Kyohokai hold, which confirms H3. However, the findings with regard to Yokokai are mixed. Specifically, the linkage between fragility and sales revenues is verified in only two of the four years. This is because, all correlation coefficients are negative. Thus, the assumption of higher fragility having an inverse association with sales is partly confirmed. Because the meaning of fragility denotes the value of entire degree of a given network after removing a specific node, it is evident that firms in Kyohokai have a higher possibility to improve sales. Conversely, all correlation coefficients in Mazda are negative means that lower fragility is associated with higher sales-as predicted. However, as the probabilities of each year are larger than 0.05, additional longitudinal data should be collected.

\section{Conclusions}

Grounded in the review of the relevant literature, this paper proposed a new approach called fragility to shed light on interfirm behaviors within network organizations known as keiretsu. Data were drawn from Yokokai in Mazda and Kyohokai in Toyota to ascertain the relationship between degree and fragility. The results look similar between both the keiretsu when we investigate the relationships between degree and sales. However, different behaviors are manifest when fragility is viewed as a determinant of sales.

\section{Directions for Future Research}

Based on the results obtained, four fiscal years of data is not sufficient to support contentions of internal validity. Because there is lack of support for $\mathrm{H} 1$ which posits a positive relationship between out-degree and sales, additional research should be conducted to replicate the findings, thus shedding greater light on the real association between these constructs. In addition to degree, other centrality indexes, such as closeness and betweenness, should be tested as determinants of corporate performance. Furthermore, the original definition of fragility in Physics is a derivative of a mathematical function. Thus, in the future the models tested in this study should be investigated using data drawn from other settings, such as, information technology, and the ship-building industry for comparative research as well as replicating the findings of this study.

\section{Acknowledgements}

This work was supported by JSPS KAKENHI Grant Number 16K01243.

\section{References}

1. Jean McGuire and Sandra Dow (2002). The Japanese keiretsu system: an empirical analysis, Journal of Business Research 55, 33-40.

2. Jean McGuire and Sandra Dow (2003). The persistence and implications of Japanese keiretsu organization, Journal of International Business Studies 34, 374-388.

3. Tsutomu Ito, Katsuhiko Takahashi, Katsumi Morikawa, Takao Ito, Rajiv Mehta, Makoto Sakamoto, Satoshi Ikeda (2016). Momentum and Its Implications in Corporate Management, Journal of Robotics, Networks and Artificial Life, 2 (4), 272-275.

4. Lance Eliot Brouthers, Yan Gao, and Stuart Napshin (2014). Keiretsu centrality - profits and profit stability: A power dependence perspective, Journal of Business Research 67, 2603-2610.

5. Takao Ito, Ryota Takida, Seigo Matsuno, Rajiv Mehta, Yoshiteru Ishida, and Makoto Sakamoto (2011). An Analysis of Firm Capacity in Mazda's Keiretsu, Artificial Life and Robotics, 16 (2, September), 248-252.

6. Takao Ito, Makoto Sakamoto, Satoshi Ikeda, Rajiv Mehta, and Yasuo Uchida (2014). A Comparative Study of Inter-firm Transactional Relationship between Kyohokai and Yokokai, Journal of Robotics, Networks and Artificial Life, 1 (3, December), 179-183.

7. Takao Ito, Rajiv Mehta, Tsutomu Ito, Makoto Sakamoto, Satoshi Ikeda, Seigo Matsuno, and Katsuhiko Takahashi 
(2015). Inter-firm Transactional Relationships in Yokokai: An Empirical Investigation Using the IDE Spatial Model, International Journal of Mathematical Models and Methods in Applied Sciences, 9 (September) 463-472.

8. Makoto Sakamoto, Satoshi Ikeda, Takao Ito, Rajiv Mehta, Seigo Matsuno, Shinya Tagawa, and Victor Berdonosov (2014). An Empirical Examination of Interfirm Capital Relationships in Mazda's Yokokai using the IDE Spatial Model, Journal of Robotics, Networks and Artificial Life, 1 (2, September), 150-154.

9. Takao Ito, Tsutomu Ito, Katsuhiko Takahashi, Makoto Sakamoto, Satoshi Ikeda and Rajiv Mehta (2015). An Empirical Research on Inter-firm Capital Relationship in Yokokai Using IDE Spatial Model, Journal of Robotics, Networks and Artificial Life, 2 (2, September), 125-131.

10. Takao Ito, Tsutomu Ito, Katsuhiko Takahashi, Rajiv Mehta, Makoto Sakamoto, and Satoshi Ikeda (2015). Euclidean Distance and Corporate Performance in the DEC Spatial Model, International Journal of Economics and Statistics, 3 (September), 102-109.
11. Takao Ito, Eiko Niki, Ryota Takida, Rajiv Mehta, Katia Passerini, and Makoto Sakamoto (2011). Transactions and Cross Shareholdings in Mazda's Keiretsu: A Centrality Analysis, Artificial Life and Robotics, 16 (3, December), 297-300.

12. Nieminen J. (1974). On centrality in a graph, Scandinavian Journal of Psychology 15, 322-336.

13. Linton C. Freeman (1978/79). Centrality in Social Networks Conceptual Clarification, Social Networks 1, 215-239.

14. Takao Ito and Makoto Sakamoto (2005). Importance Analysis of Each Firm in the Keiretsu of Toyota, Proceedings of the 2005 Information Resources Management Association, International Conference, Managing Modern Organizations with Information Technology, 930-933, May 15-18, 2005, San Diego, USA.

15. Ediger M. D., Angell C. A., Nagel S. R. (1996). Supercooled liquids and glasses, Journal of Physical Chemistry 100 (31): 13200-13212. 